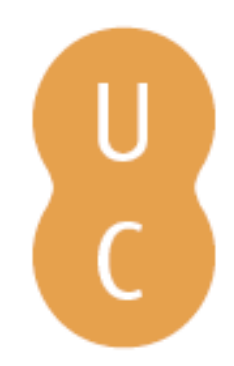

\title{
nommalina
}

\section{A Botica Colonial: apontamentos sobre saúde e alimentação na América Portuguesa (Minas Gerais - século XVIII)}

\author{
Autor(es): $\quad$ Algranti, Leila Mezan \\ Publicado por: Imprensa da Universidade de Coimbra \\ URL \\ persistente: URI:http://hdl.handle.net/10316.2/45232 \\ DOI: $\quad$ DOl:https://doi.org/10.14195/978-989-26-1721-3_5 \\ Accessed : $\quad$ 26-Apr-2023 09:54:26
}

A navegação consulta e descarregamento dos títulos inseridos nas Bibliotecas Digitais UC Digitalis, UC Pombalina e UC Impactum, pressupõem a aceitação plena e sem reservas dos Termos e Condições de Uso destas Bibliotecas Digitais, disponíveis em https://digitalis.uc.pt/pt-pt/termos.

Conforme exposto nos referidos Termos e Condições de Uso, o descarregamento de títulos de acesso restrito requer uma licença válida de autorização devendo o utilizador aceder ao(s) documento(s) a partir de um endereço de IP da instituição detentora da supramencionada licença.

Ao utilizador é apenas permitido o descarregamento para uso pessoal, pelo que o emprego do(s) título(s) descarregado(s) para outro fim, designadamente comercial, carece de autorização do respetivo autor ou editor da obra.

Na medida em que todas as obras da UC Digitalis se encontram protegidas pelo Código do Direito de Autor e Direitos Conexos e demais legislação aplicável, toda a cópia, parcial ou total, deste documento, nos casos em que é legalmente admitida, deverá conter ou fazer-se acompanhar por este aviso.

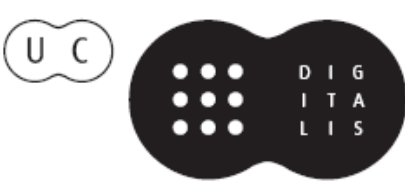


Carmen Soares

Gilene da Silva Gomes Ribeiro

(coords.)

\section{Mesas \\ LUSO-BRASILEIRAS}

\section{ALIMENTAÇÃO, SAÚdE \& GULTURA}

\section{VOLUME I}

IMPRENSA DA UNIVERSIDADE DE COIMBRA COIMBRA UNIVERSITY PRESS

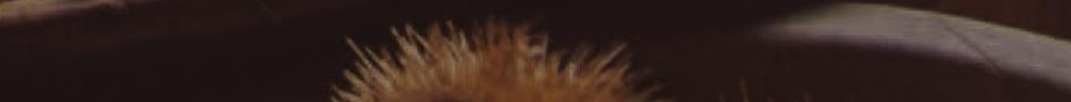




\title{
A Botica Colonial: apontamentos sobre saúde e alimentação na América Portuguesa (Minas Gerais - século XVIII) ${ }^{\mathrm{r}}$
}

\section{(The domestic pharmacy in Portuguese America: some notes on food and health (Minas Gerais XVIII century))}

\author{
Leila Mezan Algranti \\ Universidade Estadual de Campinas - Departamento de História \\ $\mathrm{CNPq}$ \\ Projeto DIAITA \\ (algranti@unicamp.br)
}

Resumo: Ao longo da colonização portuguesa na América, o intercâmbio de saberes e práticas alimentares entre os adventícios e as populações locais foi intenso e contínuo. Os cuidados com o corpo e a preservação da saúde demandaram dos colonos a exploração dos recursos naturais, tais como o conhecimento de plantas e sementes para a produção de alimentos e a confecção de medicamentos. Muitas vezes as mesmas plantas serviam à culinária e a fins terapêuticos. Com base em tratados sobre a arte de curar, o presente estudo explora as estreitas relações entre saúde e alimentação no cotidiano da capitania de Minas Gerais. Interessa especialmente compreender como os práticos portugueses incorporaram a seus saberes curativos o uso medicinal de produtos coloniais consagrados na culinária local e presentes nas refeições diárias, como o milho, a mandioca, a aguardente de cana.

PALAVRAS-CHAVE: alimentação, culinária, saúde, botica doméstica, intercâmbio cultural.

AbSTRACT: During the Portuguese colonization in America, there was an intense and continuous exchange of knowledge and dietary practices between those coming from Europe and the local populations. Preservation of the health of the settlers and their bodily care demanded employment of natural resources, such as plants and seeds, for alimentary and therapeutic purposes, which depended on an accurate knowledge of their properties. Often, the same plants served both purposes. Taking as a point of departure colonial treatises on the art of healing, this paper explores the close relationship between health and nutrition in the everyday life in the Captaincy of Minas Gerais. It aims at understanding how Portuguese apothecaries made use in their prescriptions of ordinary food products (corn, cassava, sugar cane brandy

\footnotetext{
${ }^{1}$ A investigação realizada para este estudo contou com o apoio financeiro do CNPq.
} 
and so on), known to them because they were part of their daily meals, in order to treat diseases and to restore their clients' health.

KEYWORDS: nutrition, cooking, domestic pharmacy, health, cultural exchanges.

Desde os primeiros séculos da colonização portuguesa na América, nota-se nos registros dos cronistas e nas correspondências trocadas entre missionários dos dois lados do Atlântico, a preocupação com os cuidados do corpo e a preservação da saúde dos $\operatorname{colonos}^{2}$. A distância em relação à Metrópole e o fato dos medicamentos chegarem frequentemente estragados ou não se adequarem a muitas das doenças locais incentivou a exploração e o conhecimento de plantas e sementes para a produção de alimentos e de remédios. Como bem observou Joan Thirsk, os vegetais sempre serviram a duas finalidades distintas: à alimentação e à saúde. Esses dois propósitos se misturavam na mente dos contemporâneos quando se sentavam à mesa para comer ${ }^{3}$. A participação dos vegetais e seu status nas refeições dos mais abastados, porém, variou na época moderna em função de considerações sobre seu valor nutritivo e medicinal. Para alguns tratava-se de um tipo de alimento fraco e úmido. Outros consideravam os vegetais responsáveis por curas de doenças e incentivavam seu consumo, apoiados em saberes eruditos e populares. Atento às qualidades curativas das plantas, o cronista e senhor de engenho da Bahia, Gabriel Soares de Sousa, escreveu em 1587 sobre uma erva, tida como excelente purgador:

Jeticuçu é uma erva que nasce pelos campos... deitam estas ervas umas raízes por baixo da terra como batatas, que são maravilhosas para purgar, do que se usa muito na Bahia; as quais raízes se cortam em talhadas, em verdes, que são por dentro alvíssimas e secam-nas muito bem ao sol; e tomam dessas talhadas, depois de secas...e lançadas em vinho ou em água muito bem pisado se dá a beber ao doente de madrugada e faz maravilhas ${ }^{4}$.

Com o desenvolvimento da colonização, nos séculos seguintes, o aumento do contato com os índios proporcionou o surgimento do que poderíamos chamar de uma botica colonial, constituída por medicamentos produzidos a partir da incorporação de saberes indígenas sobre a natureza brasílica, mas também de conhecimentos trazidos pelos portugueses, uma vez que estes

2 Sobre os missionários e a relação com a saúde e as artes de curar ver: Leite 1953.

3 Thirsk 2006: 287.

4 Sousa 1971: 207; jeticuçu é uma palavra indígena que define uma planta, também conhecida por outros nomes, como por exemplo, batata de purga, jalapa, mechoacão, ruibarbo branco. Seu nome científico é Convolvulus sperculatus. 
identificavam, no Novo Mundo, plantas semelhantes àquelas disponíveis na Europa e das quais faziam uso no tratamento de doenças.

Dessa forma, no domínio da saúde e da arte de curar, os jesuítas tiveram uma contribuição extremamente importante, uma vez que as boticas que montaram em seus colégios, tanto no Brasil, como em outras localidades do império português, fizeram fama na época ${ }^{5}$. Como chamou atenção Daniela Calainho, "a escassez de médicos leigos, formados por escolas de medicina na Europa, pelo menos até o século XVIII, fez dos jesuítas os responsáveis quase que exclusivos pela assistência médica no primeiro século de colonização do Brasil”" Alguns deles, diz a historiadora, já vinham formados nas artes médicas, mas a maioria acabou por atuar informalmente como físicos e sangradores.

Essa curiosidade sobre as formas locais de curar, movida em grande parte devido à necessidade de sobreviver em um ambiente desconhecido e muitas vezes hostil, não cessou com o passar do tempo, como é possível perceber em tratados médicos e cirúrgicos escritos no século XVIII, os quais mencionam as propriedades curativas de certas plantas alimentícias nas Minas Gerais. Essa foi uma região de colonização tardia - se comparada ao litoral do Nordeste do Brasil - em uma época na qual os portugueses já haviam acumulado muitas experiências nos trópicos.

A divulgação da existência de ouro e posteriormente de diamantes no sertão das Gerais atraiu, como é bem conhecido, um grande contingente populacional originário da própria Colônia, assim como de Portugal e das ilhas atlânticas ${ }^{7}$. O que se observa nos relatos de época é que desde as primeiras décadas daquele século, a falta de alimentos, de remédios e de médicos, além do pouco conhecimento da região provocou períodos de intensa carestia de alimentos e de epidemias na capitania ${ }^{8}$. O jesuíta André João Antonil (João Antônio Andreoni), por exemplo, celebrizou em sua obra Cultura e Opulência do Brasil por suas drogas e minas (1711), a imagem da fome nas Gerais, no início do Setecentos, ao comentar que os mineiros morriam à míngua "com uma espiga de milho na mão sem terem outro sustento" ${ }^{9}$. Tal situação estimulou não só a produção local de alimentos, como o registro de itinerários de viagem para se chegar à região mineradora, bem como de tratados sobre as doenças mais comuns, a fim de orientarem aqueles que se embrenhavam

5 Calainho 2005: 65. São famosas, por seus equipamentos e livros as boticas jesuíticas dos colégios de Salvador de do Rio de Janeiro.

6 Ibid: 64.

7 Souza 1982: 24.

8 Dias 2002: 46.

9 Andreoni s/d: 267. 
por suas matas cerradas, sujeitos a febres e disenterias, a vários tipos de males que acometiam os olhos, além do risco de picadas de animais venenosos.

É nesse quadro de extremas necessidades vivenciadas durante o povoamento e a exploração das Minas, que se pode situar três documentos extremamente interessantes sobre o cotidiano daquela sociedade e que oferecem informações sobre o tratamento de doenças na região, entre os quais aqueles associados às plantas alimentícias que interessam destacar aqui. Refiro-me ao Erário Mineral (1735), registro do exercício prático do cirurgião e minerador português Luis Gomes Ferreira e ao Códice Costa Matoso (1750), um amplo e conhecido conjunto de documentos compilados pelo ouvidor geral da comarca de Ouro Preto, Caetano da Costa Matoso ${ }^{10}$. Ambos os documentos foram publicados na primeira metade do século XVIII ${ }^{11}$. O terceiro registro é a obra intitulada Governo de Mineiros de autoria de José Antônio Mendes, também cirurgião aprovado em Lisboa em 1739 e, por sua vez, nomeado Comissário Geral do cirurgião-mor do Reino em toda a América. Ele teve uma trajetória semelhante àquela de seu colega de profissão Luís Gomes Ferreira, pois também era originário do norte de Portugal, e chegou na Bahia, vivendo depois em Minas, por mais de duas décadas. No distrito Diamantino serviu no Hospital do Serro. Ele também registrou suas experiências curativas nos trópicos, reforçando a ideia da importância de que os cirurgiões atingiram posição privilegiada na Colônia, assumindo funções e atitudes próprias de médicos, ao prescreverem medicamentos e escreverem sobre matéria médica. Sua obra foi publicada em Portugal, em $1770^{12}$.

10 O cirurgião barbeiro Luis Gomes Ferreira era natural de Vila de São Pedro de Rates, Concelho de Póvoa do Varzim de onde saiu para aprender seu ofício no Hospital de Todos-os-Santos, em Lisboa. Foi cirurgião da Carreira da India. Chegou à região das Minas em 1707, como muitos outros portugueses, atraído pelas notícias de descoberta de ouro. Já teria estado anteriormente na Bahia, como cirurgião de bordo. Chegou à Minas pela região do Rio das Velhas e acabou se estabelecendo depois em Mariana e em Vila Rica. A falta de práticos nas artes de curar nas Minas o estimulou a exercer o ofício de cirurgião. O Erário Mineral é o relato das curas que realizou e de sua forma de entender as doenças. Foi publicado em 1735, após o seu retorno a Portugal, em 1732. Furtado 2002: 4-7.

11 Pouco se sabe sobre esse conjunto de documentos intitulado Códice Costa Matoso e menos ainda sobre seu compilador, segundo o coordenador da nova edição de 1999, Luciano Figueiredo, o qual realizou um estudo crítico sobre este conjunto dos documentos e sua trajetória de Portugal ao Brasil. O códice Costa Matoso compreende diferentes temáticas organizadas cronologicamente. Interessam ao presente estudo especialmente aqueles relatos dedicados aos primeiros tempos da exploração das Minas e às condições de sobrevivência na região, tais como, saúde e alimentação. Ver Figueiredo 1999: 39-154. Para maiores informações sobre José Antônio Mendes e sua obra ver Moisés 2005.

12 Não era praxe cirurgiões escreverem sobre artes de curar, mas de acordo com os estudiosos do assunto, o fato de não haver muitos médicos serviu de pretexto a ambos (Mendes e Ferreira) publicarem seus registros a fim de informarem as populações locais sobre as doenças mais comuns e suas curas. Para Filgueiras, que organizou a edição do Governo de Mineiros de 2012, José Antônio Mendes seria até hoje o menos conhecido dos cirurgiões que viveram em 
Todos os três documentos receberam edições críticas recentes ${ }^{13}$; e um dos fatores que os torna relevantes para o presente estudo é o fato de serem um testemunho de que para os contemporâneos (leigos ou profissionais) havia uma estreita relação entre alimentação e saúde. Isto é, a ideia de que a boa saúde advém da boa alimentação estava plenamente disseminada na época. Posição, aliás, que se encontra na base de diferentes concepções de cura ao longo da história, como se pode avaliar pela presença ainda marcante da teoria hipocrática na medicina da era moderna, a qual fazia da ingestão de alimentos ponto alto do processo de cura ${ }^{14}$. A questão que se coloca, no entanto, é o que seria considerado uma alimentação saudável no século XVIII? $\mathrm{Ou}$ como se deveria proceder em termos alimentares frente a uma doença? E até mesmo, como fazer uso dos alimentos para curá-las? ${ }^{315}$

As artes de curar na América portuguesa constituem um campo de estudos plenamente consolidado na historiografia brasileira, no qual atuam tanto historiadores das ciências, como da sociedade e cultura, com os quais a recente história da alimentação na América portuguesa tem aprendido muito e procurado dialogar. Trata-se de estudos que abordam várias questões, como por exemplo as farmacopeias portuguesas, nas quais se identificam plantas do Brasil ou processos de cura com referências a práticas mágicas juntamente com medicamentos diversos ${ }^{16}$. Também participam dessa abordagem estudos sobre os herbários na Europa Moderna com suas contribuições para a história da botânica e da medicina ${ }^{17}$. Outro nicho de pesquisa são os trabalhos dedicados às trajetórias de vida de médicos, cirurgiões e boticários, assim como aqueles que se atém ao pensamento médico e aos tratados de medicina e de cirurgia da época ${ }^{18}$. Sem falar nas boticas jesuíticas aqui já referidas e nas receitas dos boticários, assim como na composição dos medicamentos ${ }^{19}$.

Minas, no século XVIII, e publicaram suas experiências de cura. Para mais informações sobre este personagem ver: Moisés 2005: 64-75.

${ }_{13}$ Erário Mineral, Furtado 2002; Códice Costa Matoso, Figueiredo 1999; Governo de Mineiros, Filgueiras 2012.

14 Até a reforma da Universidade de Coimbra, a medicina humoral imperava nos estudos médicos em Portugal, tendo Hipócrates (460 a.C. - 370 a.C.) como um dos seus mais famosos fundadores. Suas concepções insistiam na ideia de que a doença era um desequilíbrio dos humores que compunham o corpo humano, podendo ser recuperado e mantido graças a métodos não só dietéticos, mas também cirúrgicos e farmacológicos. Ver sobre o assunto: Mazzini 1998: 254-265.

15 O projeto de pesquisa intitulado "As especiarias na Botica e na cozinha", apoiado pelo CNPq entre 2009-2011, procurou responder algumas dessas perguntas: ver Algranti 2012.

16 Ver por exemplo: Ribeiro 1997; Viotti 2012; Sousa 2013.

17 Ver sobre o assunto: Carneiro 2002: 13-85.

18 Sobre tais temáticas ver: Beltrão 1999; Furtado 2002; Wissenbach 2002.

19 Figueiredo 2008. 
Sob o prisma da alimentação/saúde, propriamente dito, no entanto, ainda temos poucos trabalhos referentes ao período colonial, embora seja uma área de interesse crescente ${ }^{20}$, estimulada pelo amplo debate presente na historiografia internacional, bem como por estudos dedicados a outros períodos da história do Brasil. Quanto à história da alimentação na América portuguesa, por sua vez, destacam-se os trabalhos dedicados a certos produtos alimentícios e suas formas de produção e consumo, como por exemplo, o milho, a aguardente, o cacau, bem como estudos dedicados ao abastecimento de gêneros alimentícios e às práticas alimentares ${ }^{21}$. Em termos de abordagens, a cultura material, a transmissão de saberes e o intercâmbio alimentar - este último, resultado do contato intenso entre culturas diferentes ocorrido em terras brasílicas - têm atraído a atenção dos historiadores da Colônia ${ }^{22}$.

É exatamente um desses aspectos - o intercâmbio cultural em termos alimentares e curativos - que gostaria de destacar aqui a partir dos três documentos selecionados para análise (Erário Mineral, Códice Costa Matoso e Governo de Mineiros). Interessa detectar como os práticos portugueses, envolvidos nos tratamentos dos doentes, incorporaram a seus saberes curativos europeus, o uso medicinal de produtos coloniais consagrados na culinária local. Ou seja, compreender os usos que eles fizeram de um segmento da botica colonial constituído por plantas e ervas consumidas na alimentação cotidiana. Aclimatadas ou autóctones muitas dessas plantas encontravam-se com frequência na farmácia doméstica e na mesa de indivíduos de diferentes segmentos sociais. Como o conjunto de plantas que cumpriam tais funções é bastante extenso, serão privilegiadas neste estudo, aquelas tidas como alimento básico e fundamentais para a sobrevivência na Colônia, como o milho e a mandioca. Nesse sentido, a exemplo de Fernand Braudel, poderíamos chamá-las de plantas dominantes ou de civilização ${ }^{23}$. Contudo, não é possível deixar de lembrar que havia outras plantas muito valorizadas devido a ambas as utilidades: medicinais e alimentícias, como a cana de açúcar, com a qual se fabricava aguardente, além de vários tipos de ervas e sementes utilizadas

20 Didone 2007.

21 Basso 2014; Chamboleyron 2007; Silva 2015; Couto 2007; Magalhães 2004.

22 Para a abordagem das práticas alimentares a partir do enfoque da cultura material, ver: Meneses 2016 e sobre o intercâmbio cultural, ver Panegassi 2013: 81-97.

23 Embora Braudel não tenha incluído a mandioca entre as plantas dominantes de civilização - como fez com o trigo, o arroz e o milho - por considerar que na América, ela "só serviu culturas primitivas e regularmente medíocres" (Braudel 1997: 139), cabe observar que estudos posteriores consideraram a mandioca um dos alimentos mais importantes para a subsistência dos colonos, na América portuguesa, tendo sido consumida de norte a sul e por todos os habitantes, ao longo de mais de três séculos de colonização (Cascudo 1995: 96). Assim, é possível dizer que a mandioca assumiu, no Brasil, significados semelhantes aqueles atribuídos por Fernand Braudel ao demais cereais mencionados. 
como temperos e introduzidas na culinária colonial pelos portugueses, tais como: o coentro, a mostarda, as pimentas ou a salsa.

Vejamos então primeiramente no que consistia a dieta básica em Minas Gerais, para em seguida podermos entender a participação desses alimentos no tratamento e na prevenção de doenças.

\section{i. A dieta alimentar nas Minas setecentistas}

Para compreendermos a dieta alimentar na região mineradora durante boa parte do século XVIII é preciso ter em mente dois aspectos: o primeiro é que se tratava de uma sociedade com características urbanas, embora nem sempre fosse muito clara a separação entre campo e cidade, pois as habitações possuíam roças e quintais nos quais se produzia, com frequência, o essencial para viver, conforme apontam estudos baseados em testamentos e inventários pós mortem de várias comarcas da capitania de Minas Gerais ${ }^{24}$. Minas, portanto, não era só ouro no século XVIII, como durante muito tempo a historiografia brasileira defendeu. Isso porque se no início os mineradores tiveram que enfrentar graves problemas de abastecimento, acabaram por compreender que era preciso produzir localmente parte de seu sustento. Assim, o que não era encontrado na horta poderia, em tese, ser adquirido nos mercados ${ }^{25}$.

O segundo aspecto a considerar é a influência dos hábitos alimentares dos paulistas nas regiões mineradoras (Minas Gerais, Mato Grosso e Goiás). Afinal, foram eles os primeiros desbravadores da região, sendo que de São Paulo partiam não só expedições com fins exploratórios de minérios, como também muitas outras com a finalidade de abastecer o sertão mineiro ${ }^{26}$. Tanto no primeiro caso quanto no segundo, o destaque fica por conta do milho, tido como alimento básico nas refeições e assumindo um lugar fundamental na dieta de paulistas e mineiros, pois com ele se fazia diferentes tipos de pratos. Se Sergio Buarque de Holanda já havia apontado na década de 1950, a importância do milho à mesa dos habitantes de São Paulo e consequentemente na dos mineiros, Rafaela Basso, em estudo recente, contextualizou de forma mais precisa a ideia, enfatizando que para os paulistas, esse produto estava associado à mobilidade, por ser fácil de transportar nas viagens e germinar rapidamente em caso de necessidade, ao longo dos caminhos, nos pousos mais prolongados. Ao contrário do que foi aceito durante muito tempo, eles também consumiam a mandioca na estabilidade de suas práticas domésticas, como sucedia na maior parte da América portuguesa: "Com efeito, diz a autora, o consumo da mandioca entre os paulistas pode ser sugerido pelo

\footnotetext{
${ }^{24}$ Paiva 1995; Furtado 1999: 197-212.

25 Meneses 2000: 145-150; Scarato 2014: 128-140.

26 Holanda 1994: 182-183.
} 
relato de vários cronistas", os quais como Manoel Fonseca, "não hesitaram em descrever a farinha de mandioca como parte integrante do sustento ordinário dos moradores de São Paulo"27.

Haveria, portanto, dois padrões alimentares distintos para os paulistas: quando em movimento consumiam prioritariamente milho, mas quando estavam nas vilas e chácaras aderiam à mandioca e ao trigo. Este último sim, uma peculiaridade tanto de consumo dos habitantes de São Paulo, como de exportação devido às condições climáticas dessa região.

No caso de Minas Gerais, também há registros de roças de mandioca nos inventários pós mortem ${ }^{28}$, mas foi o milho que os famosos bandeirantes levaram consigo ao descobrirem as primeiras jazidas de ouro ${ }^{29}$. Para Monica Abdala, juntamente com o feijão e a carne de porco, o milho compõe a tradicional cozinha mineira até hoje ${ }^{30}$. De acordo com a antropóloga, esse cardápio teve sua formação em dois períodos históricos: o período da mineração, cujo apogeu se deu no século XVIII; e o período da ruralização, momento de concentração da vida econômica e social nas fazendas, que sucedeu ao declínio das minas, no século XIX ${ }^{31}$. Ela destaca na culinária regional alguns pratos, tais como: o angu de milho verde, a leitoa pururuca, o tutu de feijão, e considera que, no período colonial, o milho estava presente em todas as refeições se sobrepondo à mandioca. $\mathrm{O}$ porco por sua vez, foi levado para a região pelos portugueses e, aliado "à carne de frango, era uma constante no cardápio mineiro deste período". Quanto aos feijões havia diferentes tipos nativos, mas seu consumo foi incrementado pelo hábito dos escravos africanos "o cozinharem até virar uma pasta espessa e comiam-no acompanhado de farinha, uma forma de pirão escaldado como o dos indígenas" ${ }^{32}$. Além das espécies disponíveis no Brasil, os portugueses trouxeram da África muitas variedades de feijões, mas a farinha à qual todos os documentos de época se referem, prioritariamente em Minas Gerais, é o fubá, nome africano para designar a farinha de milho.

De acordo com José Antônio Mendes - autor do Governo de Mineiros - cirurgião e observador dos costumes dos escravos:

27 Basso 2014: 102.

28 Scarato 2014: 159; Meneses 2000: 169.

29 Refiro-me ao milho graúdo e não ao milho miúdo que os portugueses conheciam e consumiam já antes da época dos descobrimentos marítimos, especialmente no norte do país, Costa 1983 MFA 16:4.

30 Abdala 2006: 120.

31 Ibid.

32 Ibid: 121. 
[...] os alimentos dos quais se sustentavam os negros em Minas, sobretudo na região do distrito dos diamantes, eram angu e feijão, comidos frios no almoço; milho mal cozido em tacho de cobre com vestígios de azinhavre para o jantar, e na ceia feijão preto com pouco sal e algum tempero, acompanhado por vezes de angu ${ }^{33}$.

Há, contudo, outro produto a destacar na dieta alimentar: a aguardente de cana de açúcar. É o próprio José Mendes quem atesta que "as refeições dos escravos eram acompanhadas de água e de cachaça da pior espécie" ${ }^{4}$. Para o mesmo autor, essa era uma dieta de baixa qualidade responsável por várias doenças que acometiam os cativos.

Cabe, porém, acrescentar que a aguardente de cana não era consumida apenas por escravos. Havia cachaça de diferentes qualidades, extraídas a partir de processos de destilação do mel da cana de açúcar, em momentos distintos da fabricação do açúcar ${ }^{35}$. Os portugueses conheciam e consumiam aguardentes destiladas de vinho, as quais eram exportadas para as suas Conquistas. Daí as tentativas da Coroa portuguesa em restringir até proibir a produção da aguardente de cana no Brasil, a fim de evitar a concorrência com os vinhos importados de Portugal $^{36}$. A medida não parece ter surtido efeito pois foi reeditada várias vezes. Além disso, sabe-se por estudos dedicados à economia mineira que a produção de açúcar e de aguardente cresceram rapidamente nas primeiras décadas do século XVIII ${ }^{37}$. Analisando a documentação referente aos quilombos formados por escravos fugidos, na capitania de Minas Gerais, Carlos Magno Guimarães evidenciou a importância do comércio local e do consumo de cachaça vendida clandestinamente por taberneiros e negras quitandeiras aos quilombolas ${ }^{38}$. Estes também produziam a bebida nos quilombos, plantando a própria cana de açúcar. A historiografia tem mostrado em vários estudos sobre a economia da região mineradora, bem como sobre as técnicas de fabricação e consumo da cachaça, que se tratava de produto consumido por homens e mulheres de todos os segmentos da sociedade, tanto no dia a dia como nas ocasiões festivas ${ }^{39}$. Vendida nas tabernas e botequins das vilas mineiras - espaços de sociabilidade de escravos e de homens pobres - ou

${ }^{33}$ Mendes 2012: 42. Com a farinha de mandioca ou de milho (fubá) fazia-se o angu (água adicionada à farinha). Com o milho pilado a canjica era o alimento trivial.

${ }^{34}$ Ibid.

35 Figueiredo e Venâncio 2012: 23.

36 Ibid: 29.

37 Valadares 2005: 130.

38 Guimarães 2005: 115.

39 Algranti 2005: 84-85. 
nos pousos na beira dos caminhos, a cachaça era a bebida que se encontrava sempre presente, servindo muitas vezes para enganar a fome $e^{40}$.

Em termos de dieta cotidiana, portanto, a cachaça, o milho em suas diferentes formas de processamento: cozido, assado ou transformado em farinha, acrescido do feijão e da carne, constituíam a base da alimentação na região mineradora. Como esclareceu Paula Pinto e Silva em sua análise sobre a culinária colonial, no tripé alimentar composto por farinha, feijão e carne constavam dois produtos secos e um molhado ${ }^{41}$.

Observando as reações e os processos químicos que tais produtos alimentícios provocavam no organismo humano, os colonos foram compondo com eles receitas domésticas para aplacar dores, curar doenças digestivas e outros males que acometiam a população. Assim, se esses alimentos cotidianos serviam para a manutenção da vida dos vassalos de sua Majestade no ultramar - um elemento importante para a continuidade da colonização - participavam também como "medicamentos" nos tratamentos que a Colônia oferecia para certas doenças, compondo o que poderíamos chamar de botica colonial ${ }^{42}$. É sobre alguns desses procedimentos que gostaria de tratar a partir dos três registros de época selecionados.

\section{Os CUIDADos COM A SAÚdE E A COMIDA DE TODO DIA}

De acordo com a medicina hipocrática/galênica divulgada no período em estudo, a doença era causada por um desequilíbrio dos humores que compunham o organismo humano. Ou como explicou Licurgo Santos Filho, devido às condições climáticas ou a fenômenos astronômicos, aos desregramentos alimentares ou sexuais, a estados emotivos e também devido a malefícios e feitiços ${ }^{43}$.

No caso da alimentação, de acordo com tratados médicos europeus da primeira metade do século XVIII, os quais acompanhavam o pensamento de Galeno, uma forma de se preservar a saúde consistia na moderação no ato de comer. Isso significa que uma alimentação saudável consistia em não cometer excessos de comidas e, especialmente de bebidas.

O médico Bernardo Ramazzini (1633-1714) da Universidade de Pádua, por exemplo, autor de La Salute dei Principi, é um representante dessa forma de pensar. Seus escritos nos permitem entender o que seria uma alimenta-

${ }^{40}$ Guimarães 2005: 110-111.

${ }^{41}$ Silva 2005: 127.

${ }^{42}$ Sergio Buarque de Holanda refere-se, em capítulo famoso, à "botica da natureza”, da qual participaria o que chamou de "farmacopeia rústica", ou seja, receitas compostas com substâncias da flora e também da fauna dos nossos sertões. Porém, neste estudo, ele explorou bem mais a última. Holanda 1994: 77.

43 Santos Filho 1991 v2: 176. 
ção saudável na época ${ }^{44}$. Publicada originalmente em latim, em Pádua, no ano de 1710 e dedicada ao príncipe Francisco D'Este, a obra continha um conjunto de observações referentes à prevenção das doenças mais comuns da nobreza europeia ${ }^{45}$. Os cuidados com a alimentação ocupavam um lugar de destaque nesse sistema preventivo dirigido à saúde do corpo e da mente, o qual em síntese, se poderia definir como um regime de "vida sóbria". Aliás, a expressão serviu de título a outro livro do mesmo autor: Vita Sobria, que era de fato, um comentário ao tratado de Alvise Cornaro (1484-1566), sobre as vantagens da vida sóbria, conforme explicitado no próprio subtítulo do livro de Ramazzini ${ }^{46}$. Em ambos os livros, o autor defendeu a temperança alimentar. Isto é, moderação no comer e beber, pois essa seria a base ou a pilastra da saúde e longevidade dos indivíduos. Nas suas próprias palavras:

Coloquemos de lado a lenda, da qual se serviram os mitólogos para esconder os mistérios ao povo inocente e reconheçamos que não há nada que viole tão desastradamente a saúde dos príncipes do que a intemperança no comer e beber; é indispensável que o médico dos príncipes preste a máxima atenção sobre tal aspecto e que os avise adequadamente enquanto é tempo, sobre as consequências que podem resultar para a saúde, isto é, a perda de bem-estar ${ }^{47}$.

Era, portanto, na alimentação cotidiana que Ramazzini acreditava que se deveria depositar as expectativas para um vida saudável. Nesse sentido, alertou sobre o abuso do consumo de carnes consideradas "pesadas" e de difícil digestão, como as carnes bovina, de porco e de lebre, a fim de se evitar a gota e as cólicas renais, doenças muito frequentes entre os membros das elites. $\mathrm{O}$ mesmo afirmou sobre a carne das aves aquáticas e de alguns peixes. Para este médico setecentista, as carnes de carneiro e das aves que voam seriam mais leves e apropriadas àqueles que não praticavam exercícios físicos, como os príncipes, os quais, acreditava que viviam no ócio. Em termos de alimentos saudáveis, considerou o pão branco e bem assado um gênero idôneo para a manutenção da saúde e prolongamento da vida, pois "produzia no organismo excelente nutrição". Quanto ao beber, defendia o mesmo princípio da

44 Considerações sobre o pensamento de Ramazzini e seus contemporâneos referentes às relações entre alimentação e saúde foram feitas por nós em estudo anterior: Algranti 2012: 13-28.

45 Ramazzini, La Salute dei Principi, trad. de Francesco Carnevale, Florença, Editoriales Tosca, 1992 (1710). A obra mais conhecida do autor é De morbis artificum Diatriba (1700), a qual abordou a saúde dos trabalhadores pioneiramente.

46 Bernardo Ramazzini. Vita Sobria: annotazione al Trattato di Alvise Cornaro sui vantaggi della vita sobria, trad. de Francesco Carnevale, Florença, Editoriales Tosca, 1993 (1714). O Discorso sulla vita sobria de Cornaro é datado de 1558.

47 Ramazzini 1992: 50. Para uma análise semelhante sobre este aspecto do pensamento médico da época moderna, ver Algranti 2012: 16-18. 
moderação. Sem pretender que na mesa dos príncipes faltassem bons vinhos, aconselhava que se escolhessem aqueles que não fizessem danos à saúde, de preferência vinhos "mais antigos" e com "menor quantidade de tártaro" ${ }^{48}$.

Posição semelhante foi adotada pelo português, Francisco da Fonseca Henriquez, médico de D. João V e contemporâneo de Ramazzini, ao advogar as utilidades do consumo moderado do vinho, advertindo para os danos de seu uso excessivo consumo ${ }^{49}$. Contudo, no livro de sua autoria, Ancora Medicinal para conservar a vida em Saúde (1721), ofereceu mais detalhes e recomendações não só sobre os vários tipos de vinho, mas no que toca à alimentação em geral, uma vez que esteve atento, às diferenças etárias e ao "temperamento" dos consumidores (quente - frio; seco - úmido), às formas de consumo, aos horários das refeições e, especialmente, às propriedades dos alimentos e às suas virtudes medicinais. Nesse sentido, apresenta uma longa lista de produtos e de seus benefícios para a saúde, seguindo a lógica hipocrática dos contrários para equilibrar os humores.

De acordo com os mesmos princípios e valorizando o papel da alimentação no tratamento dos pacientes, os práticos da medicina na Colônia, na primeira metade do século XVIII, não só recomendavam dietas reconfortantes aos doentes, como utilizavam "remédios empíricos", produzidos à base de alimentos, a fim de controlarem os problemas de saúde. Um exemplo interessante se encontra no tratado de Luis Gomes Ferreira ao relatar os procedimentos adotados no tratamento de uma perna dilacerada em um acidente no qual uma árvore tombou sobre a mesma. Diz o boticário:

[...] por estar o pobrezinho desconfiado [de] que ficava sem a sua perna, o consolei, dizendo que havia de ficar com ela, e que comesse algumas coisas engrossantes, como franga ou galinha cozida com arroz e beldroegas, mão e pés de boi cozidos com arroz, ou sem ele, usando deste mantimento o mais tempo que pudesse, por ser para o intento o de mais utilidade que os outros; e que também podia comer carne de vaca cozida e assada, quando tivesse falta dos sustentos; e que todos os dias de manhã e à noite molhasse a perna com aguardente bem quente para não apodrecer e gangrenar-se, que era o que mais temia, por estarem os nervos, carne, ossos e músculos pisados ${ }^{50}$.

O comentário deixa claro, que uma dieta "engrossante", isto é, substanciosa, seria composta de carne de vaca, arroz e galinha cozida, enquanto a aguardente participaria como emplastro. Ao que tudo indica, a dieta recomendada não continha os produtos ordinários da terra, aos quais a população aderia coti-

\footnotetext{
48 Ramazzini 1992: 61-63-64/70-71.

49 Henriquez 2004: 239.

50 Ferreira 2002, vol. 1: 476.
} 
dianamente, tais como o milho, o feijão, o porco e a cachaça. Alimentos que segundo o mesmo cirurgião eram pouco nutritivos, o que o fazia defender, inclusive, moderação nas sangrias como se percebe no tratamento que propôs para um paciente com pontadas:

Assim se irão continuando as sangrias com moderação, porque neste clima é muito necessário poupar forças, a respeito dos mantimentos serem de pouca substância e pouco nutritivos, por cuja causa caem as forças dentro de poucas horas e não dias ${ }^{51}$.

Embora os produtos locais não tenham sido valorizados no depoimento do boticário, é possível vê-lo como um testemunho do que Ferreira considerava uma alimentação adequada para fortalecer o paciente, bem como dos usos que fazia da aguardente. Esta propriedade contra a gangrena ou de higienização dos tecidos ulcerados é um dos benefícios da cachaça geralmente mencionado nos documentos de época. O autor do Erário Mineral, porém, exaltou-o enfaticamente:

[...] não há remédio mais singular, nem mais pronto, nem que tenha as virtudes da aguardente nestas Minas; porque tenho usado dele milhares de vezes; não houve uma em que deixasse de reconhecer a sua rara virtude, nem experimentasse mau sucesso; e para impedir gangrenas não há outro ${ }^{52}$.

Para este cirurgião português, a aguardente de cana era bom remédio para curar apostemas depois de lancetados e chagas profundas. Além de ser indicado para mordida de cão e picadas de cobras venenosas. Era também capaz de resolver problemas de surdez e curar resfriamentos ${ }^{53}$. Combinada a outras ervas, a aguardente de cana era também produto indispensável em vários emplastros.

Apesar de não ser um prático nas artes de curar, o ouvidor geral de Ouro Preto, também louvou os benefícios medicinais da aguardente de cana: "Esta aguardente - diz Costa Matoso - tem muito gasto, porque não só a que se gasta em várias enfermidades, como dores, inflamações e feridas para os olhos e surdez e, em conclusão, é muito medicinal, mas a que mais se gasta é pelas tabernas a que bebem os pretos e ainda muitos brancos a gostam" ${ }^{54}$.

Além da aguardente e do açúcar propriamente dito, dois outros produtos derivados da cana de açúcar eram utilizados em processos de cura: a rapadura e o mel de tanque. Este último consistia no melaço que escorria das formas

\footnotetext{
51 Ibid: 261.

52 Ibid: 478.

${ }^{53}$ Ferreira 2002 vol. 2: 707-708.

${ }_{54}$ Matoso 1999 vol. 1: 771.
} 
de açúcar e caía no tanque, resultante da fabricação do açúcar. Misturado a raízes específicas fervidas, como por exemplo a da butua e do picão, era considerado bom remédio para obstruções intestinais ${ }^{55}$.

No caso do açúcar, suas qualidades medicinais foram exaltadas, muito antes dele se tornar um alimento corriqueiro e indispensável na dieta europeia, a partir da sua produção em grande escala, no século XVII. Não causa estranheza, portanto, sua presença em muitas das receitas disponíveis nos tratados consultados sobre a arte de curar em Minas Gerais, inclusive como adoçante de remédios amargos ${ }^{56}$.

O mesmo sucedia com a rapadura que participava das receitas como substituto do açúcar, como se pode observar em uma proposta do autor do Governo de Mineiros para o tratamento de pontadas ${ }^{57}$. Em outras preparações a rapadura compareceu ralada ${ }^{58}$ e às vezes em quantidades bem razoáveis como na receita para obstruções, na qual José Antônio Mendes mandou raspar ou pisar uma rapadura "grande e boa" e colocá-la para ferver em água com raízes de capeba e salsa, a fim de preparar uma "garapa" para o doente tomar no lugar de água ${ }^{59}$.

Quanto aos demais produtos presentes na dieta básica, na região das Minas Gerais, entre os quais o milho, a mandioca e as carnes de porco ou de frango, esses também participavam nos procedimentos de cura com fins específicos.

Com relação à mandioca e suas utilidades alimentares, encontramos vários registros no Códice Costa Matoso, tanto em relação às espécies disponíveis quanto ao modo de fabricação da farinha. Os informantes do ouvidor de Ouro Preto alertaram, por exemplo, sobre a mandioca brava e seu caldo venenoso, esclarecendo como retirá-lo. Enalteceram também suas qualidades de alimento básico, observando que a farinha de mandioca servia de pão "ao comum das gentes, especialmente lançada em caldo grosso" ${ }^{60}$. Foi, porém, a farinha puba ou fresca aquela que recebeu mais atenção no tratamento de doentes. Quando está mole, diz o autor do registro, "tem um cheiro que parece podre e por isso lhe chamam mandioca puba; é boa". Mas quando se encontrava seca e bem peneirada, informou que era usada em caldos chamados carimã, os quais se davam "aos tísicos, porque nutrem e refrescam" ${ }^{1}$. O mesmo foi lembrado em relação ao aipim branco, um tipo de mandioca usado na preparação de

\footnotetext{
55 Ferreira 2002 vol. 1: 436.

56 Ibid: 283.

57 Mendes 2012: 94.

58 Ibid: 95.

59 Ibid:105.

${ }^{60}$ Matoso 1999 vol. 2: 776.

61 Ibid: 782 .
} 
mingaus ou caldos bem temperados, oferecidos "a gentes doentes e de pouca substância", denominados "mingaus de carimã" ${ }^{2}$. Para o mesmo observador, a farinha de mandioca era mais sadia do que a de milho. Comentou, porém, que "consumida em demasia, provocava tersóis", o que a de milho, segundo ele, não só não fazia, como ao contrário, parece que "os aquieta" ${ }^{63}$.

Quanto ao milho, menciona-se no Códice Costa Matoso que possuía valor medicinal, mas não localizamos especificações nesse sentido. As referências limitam-se às "muitas comidas que se fazem de milho". De acordo com os informantes, estas variavam desde o grão para sustento dos animais a quitutes mais elaborados. A partir do cuscuz de milho torrado, por exemplo, fabricava-se um tipo de biscoito grosso consumido nas jornadas. Misturandose melado de cana, amendoim e farinha de milho obtinha-se "doces como o pé de moleque". Com o fubá, além do "angu para os negros cozido em um tacho de água até secar", preparava-se a broa de milho que se diferenciava daquele por estar "esta cozida no forno e levar sal" ${ }^{64}$. Para o cirurgião Luis Gomes Ferreira, porém, o milho proporcionava benefícios curativos, sendo recomendado assado ou arrebentado (pipoca) no tratamento de azia ${ }^{65}$. Em casos de "pontadas de causa fria, geralmente sem febre", um emplastro feito à base de farelo de milho grosso, de alecrim ou de erva de santa maria, surtia bons efeitos ${ }^{66}$. Seguindo o mesmo princípio na cura de obstruções do fígado ou do baço, o mesmo prático sugeria ao doente que ingerisse alguns medicamentos e que fizesse compressas e emplastros na região obstruída. Em sua composição entravam cebolas brancas, banha de porco, alhos, azeite doce ${ }^{67}$.

Nos documentos consultados, contudo, os alimentos mais comumente recomendados no tratamento dos enfermos foram os caldos de frango e de galinha, assim como suas carnes bem cozidas. Tais aves eram valorizadas nas dietas como sustento, mas também para acalmar dores e febres. Trata-se de um tipo de tratamento tradicionalmente recomendado por médicos e cirurgiões, na Europa, e que nas Minas Gerais encontraram repercussão, sendo consumidos após vomitórios, sangrias e purgas, bem como por aqueles que possuíam estômagos fracos ou dietas revigorantes ${ }^{68}$. Afinal, na maior parte dos casos, os doentes deveriam evitar gorduras e produtos de difícil digestão. Aliados a produtos da terra, eles compunham o receituário básico dos boticários locais. Nota-se, portanto, que os alimentos participavam intensamente da

\footnotetext{
62 Ibid: 779.

63 Ibid: 781.

${ }^{64}$ Matoso 1999 vol. 2: 783.

65 Ferreira vol. 1: 431.

66 Ibid: $258-259$.

67 Ibid: 303 .

68 Ibid: 303.
} 
recuperação da saúde dos pacientes e de sua preservação e estavam presentes também, conforme foi visto, no processo de cura de doenças específicas.

O caso talvez mais conhecido e que vale relembrar aqui é o tratamento para a cura do escorbuto ou mal de Luanda - nome pelo qual era mais conhecido - proposto por João Cardoso Miranda, cirurgião na Bahia e divulgado por Luis Gomes Ferreira, no Erário Mineral. Esse cirurgião nos informa ter curado vários escravos e homens brancos que contraíram a doença, à bordo dos navios, ao longo da travessia da África para a América. O tratamento consistia na ingestão de alimentos frescos, como frango ou galinha cozidos com chicórias, almeirão e frutos. Nas gengivas ulceradas (um dos sintomas da doença) recomendava-se lavá-las repetidas vezes com sal dissolvido em limão ou em vinagre e aguardente fina. Todos produtos facilmente disponíveis na despensa ou no quintal da maior parte dos habitantes. Sabe-se hoje que foi exatamente a vitamina $\mathrm{C}$ presente nos alimentos propostos neste e em outros tratamentos que acabou por salvar a vida de milhares de africanos e europeus em alto mar ou na sua chegada ao Brasil ${ }^{69}$.

É interessante observar que remédio semelhante contra o escorbuto foi proposto por José Antônio Mendes, sinal de que saberes desse tipo circulavam rapidamente na Colônia. $\mathrm{O}$ tratamento consistia em uma dieta à base de carnes de vaca, frango e cabrito, tudo cozido em cujo caldo devia-se lançar "raízes de grama, folhas de chicória, e mastruços para que o caldo fique medicinal". $\mathrm{Na}$ falta de pão, devia-se "usar para completar, farinha de mandioca"70.

Exemplos desse tipo multiplicam-se nos compêndios consultados, os quais atestam que na botica colonial os alimentos cotidianos participavam dos tratamentos de doenças juntamente com plantas medicinais e ervas aromáticas cujas particularidades podiam ser terapêuticas ou culinárias.

\section{Considerações Finais}

Os tratados sobre as artes de curar e demais documentos consultados são fontes imprescindíveis para os estudos dedicados aos tratamentos de doenças na América portuguesa e têm sido bastante valorizados e divulgados pela historiografia dedicada ao assunto, conforme observado ao longo deste trabalho. Na perspectiva da história da alimentação, no entanto, se apresentam como testemunhos das práticas alimentares na região e de sua relação com o equilíbrio e o bem-estar do corpo.

Em uma situação de contato entre povos de culturas diferentes, como foi a colonização portuguesa na América, um conjunto de práticas alimentares e de concepções de cura com alimentos foram sendo mescladas e incorporadas

\footnotetext{
${ }^{69}$ Ibid vol. 2: 695.

70 Mendes 2012: 113.
} 
pelos habitantes, a partir também da atribuição de significados simbólicos aos alimentos disponíveis. Como mostrou Rubens Panegassi, é principalmente por seus aspectos simbólicos que a alimentação assume seu papel de mediador entre dois universos culturais. Referindo-se ao contexto do século XVI, o autor deixou claro que os cronistas portugueses por meio da observação e da descrição das terras e das gentes estiveram atentos aos alimentos da terra e seus usos. "Tudo isso, diz ele, por meio de categorias cuja função era articular as evidentes novidades com os tradicionais recursos intelectuais" 71 . Poderíamos dizer que situação semelhante foi vivenciada pelos autores, cujos textos consultamos em busca de referências sobre a relação entre saúde e alimentação nas Minas coloniais.

No caso da comida de todo dia, que procuramos destacar, o que se nota é que embora alguns produtos pudessem ser vistos com reservas pelos europeus em termos nutritivos, acabaram por se constituir em investimentos no tratamento de determinadas doenças, como aconteceu com o milho ou a mandioca. $\mathrm{Na}$ ausência de medicamentos europeus disponíveis para certos males mais frequentes, como os problemas digestivos, as doenças de pele, certas febres, pneumonias, picadas de animais venenosos e edemas de todo tipo, a botica colonial entrava em ação, sendo bastante frequente a ingestão de alimentos cotidianos na forma de comida nas refeições, além de medicamentos nos quais os vegetais do Brasil participavam das preparações.

Muitos destes cirurgiões e boticários europeus que viveram no Brasil, traziam já conhecimentos sobre o mundo natural americano, antes de aqui chegarem, como bem apontou Cristina Wissenbach. Esse contato se dava por meio de escritos sobre a flora e fauna americana produzidos nos séculos XVI e $\mathrm{XVII}^{72}$. O que não impede, como sugeriu a mesma historiadora, que tais observadores - assim como os autores consultados - tenham sido obrigados a se transformar em naturalistas, reconhecendo plantas e testando seus poderes curativos nas doenças que se apresentavam ${ }^{73}$.

Dos três conjuntos de documentos consultados (Erário Mineral, Códice Costa Matoso, Governo de Mineiros) é talvez no Códice Costa Matoso onde encontraremos referências mais explícitas sobre a presença de alimentos cotidianos nos tratamentos das doenças. Talvez isso ocorra devido ao fato dos outros dois autores serem profissionais das artes de curar, com formação em Portugal e experiências profissionais anteriores no Velho Continente. Assim, embora reconheçam e façam uso de saberes indígenas e de várias plantas brasílicas em suas receitas, nota-se uma forte presença de saberes e de

\footnotetext{
${ }^{71}$ Panegassi 2013: 192.

72 Wissenbach 2002: 108-109.

${ }^{73}$ Ibid.
} 
produtos vegetais - também químicos - anteriormente conhecidos e com os quais estavam bastante familiarizados. No caso de plantas alimentícias com uso medicinal, por exemplo, a aguardente do Reino, o almeirão, a chicória, a erva doce, a salsa, o funcho e as batatas são frequentemente lembradas, sinal de que também no Reino fazia-se essa associação. Um exemplo interessante dessa postura encontra-se no Governo de Mineiros: o autor propôs uma receita de emplastros, portanto, não para ingestão, a fim de curar apostema e tumores, na qual participavam produtos alimentícios, mas o elemento principal presente na formulação, ou seja, o pão branco de trigo, era não só praticamente ausente da alimentação na Colônia, como difícil de ser adquirido. Diz o cirurgião ser o tal emplastro conhecido como micapanis, que consistia em "miolo de pão alvo aboborado em leite de peito, e pisado com gema de ovo, estendido em pano, posto na parte". Logo em seguida - talvez lembrando-se da escassez de trigo na região - sugeriu como alternativa um outro emplastro feito com bananas de $\mathrm{S}$. Tomé cozidas em leite de vaca, pisadas com gema de ovo, o qual deveria ser colocado sobre a parte afetada ${ }^{74}$.

De qualquer modo, não se pode negar a importância tanto do Erário Mineral como do Governo de Mineiros enquanto inventários das doenças mais comuns nas Minas, bem como das terapêuticas adotadas, especialmente nos tratamentos dispensados aos escravos com plantas locais. A guisa de conclusão, contudo, podemos destacar que, segundo os práticos da Colônia, era na alimentação cotidiana que se deveria colocar não só as expectativas de uma vida saudável - como preconizavam os médicos europeus Ramazzini e Henriquez - mas ao que tudo indica, também encontrar o estímulo para a recuperação e cura de algumas doenças. Conforme foi visto, neste estudo preliminar, na botica colonial, havia um conjunto de plantas, indispensáveis na dieta cotidiana, as quais participavam de forma intensa e constante da farmácia doméstica dos habitantes nas Minas Gerais setecentistas.

\section{REFERENCIAS}

Abdala, M. C. (2006), "Sabores da tradição", Revista do Arquivo Público Mineiro 42: 120. Algranti, L. M. (2005), "Aguardente de Cana e outras aguardentes: por uma história da produção e consumo de licores na América portuguesa”, in R. P. Venâncio, H. Carneiro, Alcool e drogas na história do Brasil. Alameda Editora/Puc Minas, São Paulo/Belo Horizonte, 71-92.

Algranti, L. M. (2013), "A Arte de cozinha e as plantas do Brasil - séculos XVI-XIX", in L. Koury, Usos e circulação de plantas no Brasil séculos XVI-XIX. Andrea Jakobson Estudio, Rio de Janeiro, 138-179.

\footnotetext{
${ }^{74}$ Ibid: 33 .
} 
Algranti, L. M. (2012), "Saberes culinários e a botica doméstica: beberagens, elixires e mezinhas no Império português”, Saeculum 27: 13-28.

Antonil, A.J. (Andreoni João António) (s/d). Cultura e Opulência do Brasil, por suas drogas e minas. Companhia Editora Nacional, 2. ${ }^{\text {a }}$ ed., São Paulo.

Basso, R. (2014), A Cultura alimentar paulista - uma civilização do milho? (1650-1750), Alameda Editora, São Paulo.

Braudel, F. (1997, 2. a ed.), Civilização Material, Economia e Capitalismo, séculos XVXVIII, vol. 1, Fontes, São Paulo.

Códice Costa Matoso (1999), Coleção das notícias dos primeiros descobrimentos que fez o doutor Caetano da Costa Matoso sendo ouvidor-geral das do Ouro Preto, de que tomou posse em fevereiro de 1749, 2 volumes, Coordenação Geral Luciano Raposo de Almeida Figueiredo e Maria Verônica Campos, Fundação João Pinheiro, FAPEMIG.

Calainho, D. (2005), "Jesuítas e medicina no Brasil colonial”, Tempo 19: 61-75.

Carneiro, H. (2002), Amores e sonhos da flora: afrodisíacos e alucinógenos na botância e na farmácia, Xamã Editora, São Paulo.

Cascudo, L. C. (2004), História da Alimentação no Brasil, Global Editora, São Paulo.

Chamboleyron, R. (2007), “As Especiarias da Amazônia”, Br História 1.1.

Costa, J. P. (1983), O milho e a sua cultura, Ministério da Agricultura, Florestas e Alimentação - Divulgação, Lisboa, 16: 4.

Couto, C. (2007), Arte de Cozinha - alimentação e dietética em Portugal e no Brasil (séculos $X V I I-X I X)$, Editora Senac, São Paulo.

Dias, M. O. S. (s/d), "Nos sertões do Rio das Velhas e das Gerais: vida social num frente de povoamento, 1710-1733”, in J. Furtado (org.), O Erário Mineral, Fundação João Pinheiro/Fundação Oswaldo Cruz, Belo Horizonte, vol. 1, 45-105.

Didone, D. M. G. (2007), Saúde, Alimentação e Medicamentos na província de São Paulo: o olhar de Spix Martius e Auguste de Saint Hilaire no início do século XIX, Dissertação de Mestrado, USP, São Paulo.

Ferreira, L. G. (2002), Erário Mineral, Fundação João Pinheiro/Fundação Oswaldo Cruz, Belo Horizonte/Rio de Janeiro.

Figueiredo, B. G. (2008), A Arte de Curar, cirurgiōes, médico, boticários e curandeiros no século XIX em Minas Gerais, Argentum, Belo Horizonte.

Figueiredo, L., Venâncio, R. P. (2012), “Águas ardentes: o nascimento da cachaça”, in L. Figueiredo, R. Venâncio, M. Del Priore, F. Valadares (orgs.), Cachaça: alquimia brasileira, Design Editora, Rio de Janeiro, 12-57.

Furtado, J. F. (1999), Homens de negócio: a interiorização da metrópole e do comércio nas minas setecentistas, Hucitec, São Paulo.

Furtado, J. F. (2002), “Arte e segredo: o licenciado Luís Gomes Ferreira e o seu caleidoscópio de imagens”, in J. Furtado (org.), O Erário Mineral, Fundação João Pinheiro/Fundação Oswaldo Cruz, Belo Horizonte, 3-30. 
Guimarães, C. M. (2005), “Os quilombos, a noite e a aguardente nas Minas Coloniais”, in R. P. Venâncio, H. Carneiro, Álcool e drogas na história do Brasil, Alameda Editora/Puc Minas, São Paulo/Belo Horizonte, 93-122.

Henriquez, F. da F. (2004), Ancora Medicinal para conservar a vida com saúde, Ateliê Editorial, São Paulo.

Holanda, S. B. (1994), Caminhos e Fronteiras, Companhia das Letras, São Paulo.

Leite, S. (1953), Artes e ofícios dos jesuitas no Brasil (1549-1760), Brotéria, Lisboa.

Magalhães, S. M. (2004), A mesa de Mariana, produção e consumo de alimentos e Minas Gerais (1750-1850), Annablume/Fapesp, São Paulo.

Marques, V. R. B. (1999), Natureza em boiões - medicinas e boticários no Brasil Setecentista, Editora da Unicamp, Campinas.

Mazzini, I. (1998), "A alimentação e a medicina no mundo antigo", in J. L. Flandrin, M. Montanari, História da Alimentação, Estação Liberdade, São Paulo, 254-265.

Mendes, J. A. (s/d), Governo de Mineiros mui necessário para os que vivem distantes de professores seis, oito, dez e mais léguas, padecendo por esta causa os seus domésticos e escravos queixas que pela dilação dos remédios se fazem incuráveis e as mais das vezes mortais, Organização e estudo crítico de Carlos A. L. Filgueiras. Arquivo Público Mineiro, Belo Horizonte.

Meneses, J. N. C. (2000), O Continente rústico: abastecimento alimentar nas Minas Gerais setecentistas, Maria Fumaça Editora, Diamantina.

Meneses, J. N. C. (2016), “Dossiê”, Revista Varia Historia 32.58: 21-51.

Moisés, M. R. (1997), A Ciência nos Trópicos: a arte médica no Brasil do século XVIII, Editora Hucitec, São Paulo.

Moisés, M. R. (2005), “Nem nobre nem mecânico. A trajetória social de um cirurgião na América portuguesa do século XVIII”, Almanach Braziliense 2: 64-75.

Paiva, E. F. (1995), Escravos e Libertos nas Minas Gerais do século XVIII: estratégias de resistência através dos testamentos, Annablume, São Paulo.

Panegassi, R. L. (2013), O Pão e o vinho da terra: alimentação e mediação cultural nas crônicas quinhentistas sobre o Novo Mundo, Alameda, São Paulo.

Ramazzini, B. (1992), La Salute dei Principi, Editoriales Tosca, Florença.

Ramazzini, B. (1993), Vita Sobria: annotazione al Trattato di Alvise Cornaro sui vantaggi della vita sóbria, Editoriales Tosca, Florença.

Santos Filho, L. C. (1991), História geral da medicina brasileira, Editora Hucitec/Editora da Universidade de São Paulo, São Paulo.

Scarato, L. (2014), Os Caminhos do ouro nas Minas Setecentistas: contrabando, cotidiano e cultura material, Annablume/Fapesp, São Paulo.

Silva, P. P. (2005), Feijão, farinha e carne-seca: um tripé culinário no Brasil Colonial, Editora Senac, São Paulo.

Sousa, C. R. (2013), “As práticas curativas na Amazônia colonial: da cura da alma à cura do corpo 1707-1750", Amazon Revista de Antropologia 5: 362-384, Disponível em: <http://www.periodicos.ufpa.br/index.php/amazonica/article/ viewArticle/1498>, Acesso em: 02 fev. 2016. 
A Botica Colonial: apontamentos sobre saúde e alimentação na América Portuguesa (Minas Gerais - século XVIII)

Sousa, G. S. (1971), Tratado Descritivo do Brasil em 1587, Companhia Editora Nacional, São Paulo.

Souza, L. M. (1982), Desclassificados do Ouro: a pobreza mineira no século XVII, Editora Graal, Rio de Janeiro.

Thirsk, J. (2006), Food in Early Modern England: phases, fads, fashions 1500-1760, Continum Books, Londres.

Valadares, V. (2005), “O consumo de aguardente em Minas Gerais no século XVIII: uma visão entre os poderes metropolitano e colonial”, in R. P. Venâncio, H. Carneiro, Álcool e drogas na história do Brasil, Alameda Editora/Puc Minas, São Paulo/Belo Horizonte, 123-140.

Viotti, A. C. de C. (2012), As práticas e os saberes médicos no Brasil colonial (1677-1808), Dissertação de Mestrado, UNESP, Franca.

Wissenbach, M. C. C. (s/d), "Gomes Ferreira e os símplices da terra: experiências sociais dos cirurgiões no Brasil colonial”, in J. F. Furtado (org.), Erário Mineral, Fundação João Pinheiro/Fundação Oswaldo Cruz, Belo Horizonte, 107-150. 